\title{
Deslizamento de rodados de tratores de pneus em diferentes operações agrícolas ${ }^{1}$
}

\author{
Hêner Coelho²*, Haroldo Carlos Fernandes ${ }^{3}$, Diogo Santos Campos ${ }^{4}$, \\ Mauri Martins Teixeira ${ }^{5}$, Daniel Mariano Leite ${ }^{6}$
}

\begin{abstract}
RESUMO
Nos tratores agrícolas, o deslizamento dos rodados ocorre por diversos fatores, entre eles o esforço de tração necessário para deslocar determinado implemento e o tipo de superfície que está em contato com a banda de rodagem dos pneus. Este trabalho tem o objetivo de avaliar o deslizamento do rodado de pneus de um trator em diferentes sistemas de preparo do solo na cultura do milho, no município de Bambuí, Estado de Minas Gerais. O experimento foi conduzido a campo, na safrinha outonal de 2011, na Fazenda Varginha, do Instituto Federal Minas Gerais - campus Bambuí, em um Latossolo Vermelho distroférrico típico. O experimento foi montado em esquema de parcelas subsubdivididas, tendo, nas parcelas, as operações, nas subparcelas as marchas e, nas sub-subparcelas, as rotações, no delineamento em blocos casualizados, com três repetições, totalizando 81 unidades experimentais. Os fatores e níveis estudados foram (PC) preparo convencional, (CM) cultivo mínimo e (PD) plantio direto. Para cada tratamento, foram utilizadas três marchas (A2, A3 e B1), em três rotações (1600, 1900 e 2200 rpm). Pelos resultados, conclui-se que, no preparo convencional, o maior índice de deslizamento ocorre na operação de semeadura; no cultivo mínimo, na operação de escarificação e, no plantio direto, na operação de semeadura.
\end{abstract}

Palavras-chave: preparo do solo, preparo convencional, cultivo mínimo, plantio direto, milho.

\section{ABSTRACT}

\section{Wheel sliding of tractors in different agricultural operations}

In tractors, the wheel sliding is caused by several factors, including the tractive effort required to move a certain implement and type of surface that is in contact with the tire treads. This study aimed at evaluating the wheel sliding of a tractor in different corn tillage systems in Bambuí, MG, Brazil. The experiment was conducted in the field in the second crop of autumn 2011 at the Minas Gerais Federal Institute - campus Bambuí (Experimental Station) in an Oxisol Ustox. The experiment was arranged in split-plots, with the operations in the plots, the gears in the splitplots and rotations in the split-splitplots, in a randomized block design with three replications, totaling eighty-one experimental units. The factors and levels studied were: (CT) conventional tillage (MT), minimum tillage (NT) and no tillage. Each treatment used three run speeds (A2, A3 and B1) in three motor rotations (1600, 1900 and 2200 rpm). The results showed that in the conventional tillage, the highest wheel sliding occurs in the sowing operation; in the minimum tillage, the highest wheel sliding occurs in the operation of scarification; and in no tillage system in the sowing operation.

Key words: tillage, conventional tillage, minimum tillage, no tillage, corn.

\footnotetext{
Recebido para publicação em 08/09/2011 e aprovado em 04/06/2012

1 Trabalho extraído da Tese de Doutorado em Engenharia Agrícola da Universidade Federal de Viçosa.

2 Engenheiro Mecânico, M.Sc. Departamento de Ciências Exatas, Instituto Federal Minas Gerais (IFMG), Campus Bambuí, FazendaVarginha, Rodovia Bambuí/Medeiros, Km 05, Caixa Postal 05, 38900-000, Bambuí, Minas Gerais, Brasil. hener.coelho@ifmg.edu.br (*autor correspondente)

${ }^{3}$ Engenheiro Agrícola, D.Sc. Departamento de Engenharia Agrícola, Universidade Federal de Viçosa, Campus Viçosa, Avenida Peter Henry Rolfs, s/n, 36570.000, Viçosa, Minas Gerais, Brasil. haroldo@ufv.br

${ }^{4}$ Engenheiro Agrí́cola, D.Sc. Departamento de Ciências Exatas, Instituto Federal Minas Gerais (IFMG), Campus Bambuí, FazendaVarginha, Rodovia Bambuí/Medeiros, Km 05, Caixa Postal 05, 38900-000, Bambuí, Minas Gerais, Brasil. diogo.campos@ifmg.edu.br

${ }^{5}$ Engenheiro-Agrônomo, D.Sc. Departamento de Engenharia Agrícola, Universidade Federal de Viçosa, Campus Viçosa, Avenida Peter Henry Rolfs, s/n, 36570.000, Viçosa, Minas Gerais, Brasil.mauri@ufv.br

${ }^{6}$ Licenciado em Ciências Agrícolas, M.Sc. Departamento de Engenharia Agrícola, Universidade Federal de Viçosa, Campus Viçosa, Avenida Peter Henry Rolfs, s/n, 36570.000, Viçosa, Minas Gerais, Brasil. daniel.mariano@ufv.br
} 


\section{INTRODUÇÃO}

A maior incidência de utilização da mecanização agrícola ocorre no preparo do solo, que tem o objetivo de otimizar suas condições para germinação das sementes e a instalação das culturas. Além disso, a escolha do método de preparo do solo e do equipamento a ser utilizado pode auxiliar o controle das perdas de água e solo.

Llanillo et al. (2006) sintetizam os efeitos de três sistemas de manejo de solo (preparo convencional, cultivo mínimo e plantio direto). O plantio direto apresentou vantagens em elevar os níveis de matéria orgânica, a estabilidade de agregados, a compressibilidade e a condutividade hidráulica, mas aumenta a densidade do solo e resistência à penetração. Ainda segundo os autores, o preparo mínimo à base de escarificação apresenta-se especialmente eficiente em aumentar a velocidade de infiltração, a condutividade hidráulica e reduzir a resistência à penetração, situando-se intermediariamente, entre preparo convencional e plantio direto, nos demais aspectos. O preparo convencional apresentou os indicadores menos favoráveis para as propriedades físicas do solo.

Machado et al. (2005) afirmam que a escarificação proporciona menor desagregação do solo, por não provocar sua inversão, mantendo os resíduos vegetais depositados na superfície do terreno, facilitando assim o controle da erosão, melhorando a infiltração, a retenção de água, a estrutura e a porosidade do solo.

O plantio direto é o sistema mais usado no cultivo do milho, principalmente nas grandes áreas (especialmente nas regiões sul, sudeste e centro-oeste do Brasil). Já o plantio convencional é usado na abertura de novas áreas e naquelas com pastagens estabelecidas. Entre os pequenos produtores ainda predomina o sistema convencional, embora seja crescente a adoção do plantio direto (CONAB, 2011).

Furlani et al. (2005) concluíram que no cultivo mínimo houve o maior índice de deslizamento dos rodados do trator, com 9,40\%, seguido dos índices do plantio direto, com $4,90 \%$ e do preparo convencional, que foi de $4,30 \%$ de deslizamento, quando avaliaram uma semeadoraadubadora de precisão, com quatro linhas, na cultura do milho.

Almeida et al. (2010) avaliaram o desempenho energético de um conjunto trator-semeadora de precisão, sob diferentes marchas e rotações do motor e concluíram que o deslizamento dos rodados não foi afetado pela variação da rotação do motor.

Com o objetivo de avaliar a capacidade de um trator em desenvolver força de tração para uma carga de 25,00 $\mathrm{kN}$, em quatro velocidades de deslocamento e em três condições da superfície do solo, Gabriel Filho et al. (2010) obtiveram de 14,00 a $15,00 \%$ de índice de deslizamento dos rodados motrizes do trator sobre solo mobilizado; de
9,00 a 10,00\% de índice de deslizamento sobre solo firme coberto com palha de milho e braquiária, e de 6,00 a 9,00\% de índice de deslizamento sobre solo firme e descoberto.

Chioderolli et al. (2010), ao avaliarem o desempenho operacional de uma semeadora-adubadora de quatro linhas, na semeadura do milho, em função de preparo do solo convencional, conservacionista e semeadura direta, obtiveram, no preparo convencional 13,00; 12,00; 12,00; $12,00 \%$; no preparo conservacionista 14,$00 ; 13,00 ; 14,00$; $13,00 \%$ e, no plantio direto 8,$00 ; 7,00 ; 7,00 ; 7,00 \%$ para as rodas, traseira direita, traseira esquerda, dianteira direita e dianteira esquerda, respectivamente.

Masiero (2010) encontrou resultados de deslizamento dos rodados da ordem de 7,60\%, em pista de concreto; $11,90 \%$, em solo firme; $14,60 \%$, em solo com cobertura vegetal e 16,20\%, em solo mobilizado, quando avaliou o rendimento dinâmico na barra de tração de tratores agrícolas com tração dianteira auxiliar (4x2 TDA), em diferentes condições de superfície do solo.

Em face do exposto, objetivou-se, neste trabalho, avaliar o nível de deslizamento das rodas motrizes de um trator 4x2 (TDA), em diferentes sistemas de manejo do solo empregados na cultura do milho, em função da combinação de três velocidades de deslocamento do conjunto mecanizado, com três diferentes rotações do motor.

\section{MATERIAL E MÉTODOS}

O experimento foi conduzido em área pertencente ao Instituto Federal de Minas Gerais - campus Bambuí, no município de Bambuí, Estado de Minas Gerais, no período de fevereiro a junho de 2011.

A área experimental possui coordenadas centrais geográficas de $20^{\circ} 02^{\prime} 34^{\prime \prime} \mathrm{S}$ e $46^{\circ} 01^{\prime} 28^{\prime \prime} \mathrm{O}$, altitude média de 748,00 m e declividade média de $6,80 \%$. A região caracteriza-se por clima tropical e temperatura média anual de $22,50^{\circ} \mathrm{C}$

O solo da área experimental foi classificado como Latossolo Vermelho distroférrico típico, segundo Embrapa (2009). As amostras de solo para determinação da granulometria foram coletadas na faixa de 0,00 a $0,30 \mathrm{~m}$ de profundidade. Após análise em laboratório encontrou-se $0,44 \mathrm{~kg}$ $\mathrm{kg}^{-1}$ de argila; 0,36 $\mathrm{kg} \mathrm{kg}^{-1}$ de silte e $0,20 \mathrm{~kg} \mathrm{~kg}^{-1}$ de areia, indicando que o solo é de textura argilosa (EMBRAPA, 1997).

A área experimental havia permanecido em pastoreio por cinco anos, com predomínio de Braquiária (Brachiaria ruziziensis e Brachiaria brizantha).

Neste trabalho, utilizou-se a combinação de três velocidades de deslocamento do conjunto mecanizado em três rotações diferentes do motor, avaliando-se os seguintes implementos: arado de discos, grade destorroadora-niveladora, escarificador, pulverizador e semeadora-adubadora, 
em três sistemas de manejo do solo: preparo convencional, cultivo mínimo e plantio direto, no estabelecimento da cultura do milho.

O experimento foi instalado em esquema de parcelas sub-subdivididas, tendo, nas parcelas, as operações e, nas sub-parcelas as marchas e, nas sub-subparcelas, as rotações, no delineamento em blocos casualizados, com três repetições. Para a realização das análises estatísticas, utilizou-se o programa ASSISTAT (Silva \& Azevedo, 2002).

As unidades experimentais foram constituídas por parcelas com 20,00 m de comprimento e 5,00 m de largura, demarcando-se 10,00 m entre elas, no sentido longitudinal, para manobras, tráfego de implementos e estabilização dos conjuntos antes da aquisição dos dados. Acrescentaramse $10,00 \mathrm{~m}$ de cada lado nas medidas externas, para efeito de bordadura. A área total utilizada para o experimento foi de 21.000,00 m², sendo a área útil de 14.300,00 m².

A cobertura vegetal na área experimental foi proveniente de palhada de braquiária, que existia para pastagem, dessecada quimicamente, 20 dias antes da aplicação dos tratamentos. Para a coleta das amostras do material, utilizou-se um quadrado de madeira de $0,25 \mathrm{~m}^{2}$. Coletaram-se dez amostras aleatórias em toda a área experimental, que foram secas, até atingir massa constante, em estufa elétrica com circulação forçada de ar a $65,00{ }^{\circ} \mathrm{C}$, conforme metodologia descrita por Chaila (1986). O valor médio da massa de matéria seca da cobertura vegetal da área experimental foi de $8.340 \mathrm{~kg} \mathrm{ha}^{-1}$.

Na fase inicial do experimento, foram coletadas amostras de solo, para determinar o teor de água na faixa de 0,00 a 0,30 m de profundidade, correspondendo em média a 26,60\%. As amostras foram coletadas durante a determinação da resistência do solo à penetração e antes do início da aplicação dos tratamentos.

A densidade do solo foi determinada nas faixas de 0,00 a $0,10 \mathrm{~m}$; de 0,10 a 0,20 m e de 0,20 a $0,30 \mathrm{~m}$ de profundidades, em seis pontos por bloco, perfazendo um total de 18 pontos na área experimental, a média encontrada foi 1120,00; 1090,00 e 1050,00 kg m³ todo utilizado foi o do anel volumétrico, descrito pela Embrapa (1997).

A resistência do solo à penetração foi obtida com o penetrômetro eletrônico marca DLG, modelo PNT-2000. A coleta dos dados para determinar a resistência do solo à penetração foi feita na área experimental, na faixa de 0,00 a 0,50 m de profundidade, os valores médios encontrados variaram de 0,00 a $1,49 \mathrm{MPa}$.

Neste trabalho, utilizaram-se dois tratores agrícolas de pneus, um, da marca John Deere, modelo 5603, tração 4x2 TDA, com 55,22 kW (75,00 cv) de potência no motor, massa de $4500 \mathrm{~kg}$, e o outro, da marca URSUS, modelo 475, tração 4x2 TDA, com 55,22 kW (75,00 cv) de potência no motor, massa de 3575,00 kg. Este trator foi necessário para formar o comboio que possibilitou a aquisição de dados dos implementos montados no sistema hidráulico de três pontos (arado de discos e pulverizador); nesse sistema, a célula de carga foi inserida entre os dois tratores, por meio de correntes e pinos ligados à barra de tração do trator de potência e o para-choque do trator do conjunto mecanizado que foi avaliado; um arado de três discos reversível da marca Tatu, com massa de 506,00 kg; uma grade destorroadora-niveladora de 32 discos, dupla ação, tipo off-set, modelo GN, massa de 895,00 kg; um escarificador modelo ASA LASER CR-DCR, fabricado pela Stara, com cinco hastes espaçadas de 0,40 m, largura de trabalho de 2,00 m, massa de $1520,00 \mathrm{~kg}$; um pulverizador de barras marca K.O., modelo KO $600 \mathrm{IH}$ 14x12, massa de $460,00 \mathrm{~kg}$, o qual possui tanque com capacidade para 600,00 L e uma semeadora-adubadora pneumática da marca Tatu, modelo PST-3, de arrasto com quatro linhas espaçadas de $0,85 \mathrm{~m}$, com massa de 2260,00 kg.

Para avaliar o deslizamento do trator, ao tracionar os conjuntos mecanizados, foram utilizadas as seguintes marchas: $1^{\mathrm{a}}$ reduzida $\mathrm{A}\left(3,00 \mathrm{~km} \mathrm{~h}^{-1}\right), 2^{\mathrm{a}}$ reduzida $\mathrm{A}(4,20 \mathrm{~km}$ $\left.\mathrm{h}^{-1}\right)$ e $1^{\mathrm{a}}$ intermediária $\mathrm{B}\left(5,00 \mathrm{~km} \mathrm{~h}^{-1}\right)$, obtidas em condição de teste de desempenho a $2400 \mathrm{rpm}$. Cada marcha foi testada nas rotações de 1600, 1900 a 2200 rpm no motor do trator.

O índice de deslizamento das rodas motrizes do trator foi obtido a partir da contagem do número de voltas de todas as rodas do trator, com o implemento em operação e, depois, com o implemento sem carga, fora de operação.

O deslizamento foi estimado com base no número de voltas do rodado motriz do conjunto mecanizado na unidade experimental, de acordo com a equação:

$$
\mathrm{D}=\frac{\mathrm{N}_{1}-\mathrm{N}_{0}}{\mathrm{~N}_{1}} 100
$$

em que,

$\mathrm{D}=$ Deslizamento das rodas motrizes do trator (\%);

$\mathrm{N}_{0}=$ Número de voltas do rodado motriz do trator sem carga; e

N1 = Número de voltas do rodado motriz do trator com carga.

Os dados coletados foram submetidos à análise de variância e as médias dos tratamentos foram comparadas, aplicando-se o teste de Tukey a 5\% de significância.

\section{RESULTADOS E DISCUSSÃO}

\section{Deslizamento das rodas motrizes do trator no preparo convencional}

Na análise de variância para deslizamento em cada roda do trator, no preparo convencional, não foi observada significância da interação tripla entre os fatores operação 
de manejo do solo x marcha x rotação do motor, em todo o rodado. Para o deslizamento da roda dianteira esquerda (DRDE), não se verificou efeito de nenhum fator estudado; para o deslizamento da roda dianteira direita (DRDD), apenas os efeitos isolados de operação e marcha foram detectados; o deslizamento da roda traseira esquerda (DRTE) apresentou efeito significativo da rotação do motor com os outros fatores estudados (rotação x marcha e rotação x operação); no deslizamento da roda traseira direita (DRTD), apenas foi verificado efeito isolado da operação de trabalho do trator.

O DRTE apresentou coeficiente de variação nas parcelas (operações) relativamente menor $(15,82 \%)$ do que os dos deslizamentos das demais rodas, os quais variaram de 46,00 a 62,00\%. Os CVs das subparcelas (marchas) e sub-subparcelas (rotações) dos deslizamentos das quatro rodas foram semelhantes, variando de 20,00 a 32,00\%.

Na variável DRTE, observou-se que as maiores médias foram obtidas na operação de semeadura, em quaisquer das rotações utilizadas (Tabela 1). Isto foi devido à maior força de tração requerida pela semeadora-adubadora, trabalhando em solo mobilizado, o que promove maiores deslizamentos, aliando-se a isto o terreno ligeiramente inclinado, o que promove transferência de peso para o lado direito do trator, ficando o lado esquerdo mais leve, o que causa menor aderência, permitindo maior deslizamento da roda traseira esquerda (Tabela 1 ) .

Esses resultados corroboram os de Chioderoli et al. (2010), ao analisarem o desempenho operacional de uma semeadora-adubadora, em função de três tipos de preparo do solo: convencional, cultivo mínimo e plantio direto. No preparo convencional, encontraram $12,00 \%$ de deslizamento, no cultivo mínimo, 13,00\%, e, no plantio direto, $7,00 \%$ para a roda traseira esquerda.

Toledo et al. (2010) também encontraram valores para deslizamento dos rodados motrizes, que variaram entre 10,50 e $13,50 \%$, ao estudarem a variabilidade espacial da resistência mecânica do solo à penetração, da demanda energética e do desempenho operacional do conjunto trator-semeadora-adubadora, em semeadura de amendoim.

Tabela 1. Valores médios de deslizamento da roda traseira esquerda (DRTE \%) em cada operação do preparo convencional, por rotação de trabalho do motor

\begin{tabular}{lccc}
\hline Operação & \multicolumn{3}{c}{ Rotação (rpm) } \\
\hline & $\mathbf{1 6 0 0}$ & $\mathbf{1 9 0 0}$ & $\mathbf{2 2 0 0}$ \\
\hline Aração & $4,93 \mathrm{~b}$ & $3,34 \mathrm{~b}$ & $6,20 \mathrm{~b}$ \\
$1^{\text {a }}$ Gradagem & $4,75 \mathrm{~b}$ & $4,58 \mathrm{~b}$ & $5,11 \mathrm{~b}$ \\
$2^{\mathrm{a}}$ Gradagem & $4,58 \mathrm{~b}$ & $4,59 \mathrm{~b}$ & $5,10 \mathrm{~b}$ \\
Semeadura & $13,37 \mathrm{a}$ & $11,89 \mathrm{a}$ & $15,78 \mathrm{a}$ \\
\hline DMS $=1,85$ & & &
\end{tabular}

Médias seguidas de mesma letra, na coluna, não diferem estatisticamente pelo teste de Tukey a 5\% de significância.
As três primeiras operações de preparo do solo (aração, $1^{\text {a }}$ gradagem e $2^{\mathrm{a}}$ gradagem, respectivamente) apresentaram médias de DRTE estatisticamente iguais, nas três rotações do motor, próximas de 5,00\%, valor abaixo do recomendado pela ASABE (2006), para solo mobilizado, que é de 11,00 a 13,00\%. Explica-se este valor pela baixa força de tração requerida pelos implementos utilizados no preparo convencional.

O DRTE não variou, significativamente, em função da rotação do motor, em nenhuma das operações do preparo convencional, ou seja, os modelos de regressão não foram significativos. Os valores médios foram de: $\widehat{Y}_{\text {Aracão }}=$ $4,82 \% ; \hat{Y}_{1^{a} \text { Grad }}=4,81 \% ; \hat{Y}_{2^{n} \text { Grad }}=4,76 \% ; \widehat{Y}_{\text {Semead }}=13,68 \%$.

Na Tabela 2, observa-se que o teste de Tukey apontou diferenças entre médias de marchas para o DRTE apenas na rotação de $1600 \mathrm{rpm}$, tendo a marcha A2 promovido a menor média de patinagem dessa roda, nessa rotação. Nota-se, ainda, que nas duas rotações mais elevadas, as médias das marchas foram estatisticamente iguais, permanecendo abaixo do índice de deslizamento recomendado pela ASABE (2006), como já mencionado, pelo baixo requerimento de força dos implementos utilizados, podendo-se mencionar também o adequado lastreamento do trator.

Assim como em cada operação do preparo convencional, para as diferentes marchas utilizadas não foi detectada regressão significativa do DRTE em função da rotação do motor. Os valores médios foram de: $\widehat{\mathrm{Y}}_{\mathrm{A} 2}=7,79 \%$; $\widehat{\mathrm{Y}}_{\mathrm{A} 3}=7,69 \%$; $\mathrm{e} \hat{\mathrm{B}}_{\mathrm{B} 1}=8,51 \%$ (Tabela 2).

Isso é confirmado por Silveira (2008), que não constatou influência da velocidade de operação e da rotação do motor. Esse resultado evidencia que o deslizamento dos rodados do trator comportou-se como uma variável independente da velocidade de operação e da rotação do motor, quando teve o objetivo de otimizar o desempenho operacional de um conjunto trator-semeadora-adubadora, em sistema de plantio direto, em função de diferentes velocidades.

Tanto em relação ao DRDD, quanto ao DRTD, observa-se, na Tabela 3, que o teste de Tukey apontou a opera-

Tabela 2. Valores médios de deslizamento da roda traseira esquerda (DRTE \%) em cada marcha utilizada no preparo convencional, por rotação de trabalho do trator

\begin{tabular}{llcr}
\hline Marcha & \multicolumn{3}{c}{ Rotação (rpm) } \\
\hline A2 & $\mathbf{1 6 0 0}$ & $\mathbf{1 9 0 0}$ & $\mathbf{2 2 0 0}$ \\
A3 & $7,30 \mathrm{~b}$ & $6,60 \mathrm{a}$ & $9,46 \mathrm{a}$ \\
B1 & $7,76 \mathrm{ab}$ & $5,09 \mathrm{a}$ & $10,21 \mathrm{a}$ \\
\hline
\end{tabular}

DMS $=1,93$

Médias seguidas de mesma letra, na coluna, não diferem estatisticamente pelo teste de Tukey a 5\% de significância. 
ção de $2^{\text {a }}$ gradagem como a que promoveu menores médias de deslizamento, sendo que, para o DRTD, essa média não diferiu das médias obtidas com as duas primeiras operações.

Resultados semelhantes foram encontrados por Santos (2010), que verificou que os valores para o deslizamento dos rodados para as operações de aração e gradagem foram 6,60; 7,50 e 5,80\% para aração, primeira e segunda gradagem, respectivamente, ao avaliar o comportamento da cultura da melancia, sob o ponto de vista de produção, em diferentes sistemas de preparo do solo.

Não foram verificadas diferenças entre as médias de deslizamento da roda dianteira direita DRDD, entre as marchas A2, A3 e B1 (respectivas médias: 5,28 a; 5,17 a; 5,96 a; DMS $=0,82$ ).

Como antes mencionado, para DRDE, DRDD e DRTD, não se detectou interação da rotação com os outros fatores em estudo; no entanto, verificou-se que a regressão dessas variáveis em função da rotação do motor não foi significativa, isto é, não depende da operação e marcha, os valores médios foram de: $\widehat{Y}_{\mathrm{DRDE}}=5,47 \% ; \hat{\mathrm{Y}}_{\mathrm{DRDD}}=$ $5,47 \% ; \hat{\mathrm{Y}}_{\text {DRTD }}=7,18 \%$.

\section{Deslizamento das rodas motrizes do trator no cultivo mínimo}

Na análise de variância para deslizamento, em cada roda do trator, no cultivo mínimo, não foi observada significância da interação tripla entre os fatores operação em nenhuma das rodas. Para o DRDE, verificou-se o efeito significativo da operação, da marcha e da interação (rotação x operação); para o DRDD, foram observados os efeitos isolados de operação e marcha, bem como o efeito da interação (operação x marcha); o DRTE apresentou efeito significativo da operação e da interação (rotação x operação); o DRTD apresentou efeito significativo da operação de trabalho, da marcha e das interações (rotação $x$ operação e rotação x marcha).

Para DRDD e DRTD, observam-se maiores valores de CV nas parcelas (operações), o que pode ter ocorrido pela inclinação do terreno e grande quantidade de cobertura vegetal, presente na área, fazendo com que o rodado per-

Tabela 3. Valores médios do deslizamento da roda dianteira direita (DRDD \%) e deslizamento da roda traseira direita (DRTD \%) em cada operação do preparo convencional

\begin{tabular}{llc}
\hline Operação & DRDD & DRTD \\
\hline Aração & $6,20 \mathrm{ab}$ & $5,50 \mathrm{~b}$ \\
$1^{\mathrm{a}}$ Gradagem & $4,82 \mathrm{bc}$ & $6,62 \mathrm{~b}$ \\
$2^{\mathrm{a}}$ Gradagem & $2,84 \mathrm{c}$ & $5,38 \mathrm{~b}$ \\
Semeadura & $8,02 \mathrm{a}$ & $11,21 \mathrm{a}$ \\
\hline DMS & 2,73 & 3,15 \\
\hline
\end{tabular}

Médias seguidas de mesma letra, na coluna, não diferem estatisticamente pelo teste de Tukey a $5 \%$ de probabilidade. ca aderência ao solo, proporcionando maiores variações de deslizamento nas rodas do lado direito do trator. Podese verificar também que o DRTD apresentou coeficiente de variação de 23,61\% nas subparcelas (marchas), relativamente menor que o dos deslizamentos nas demais rodas, os quais variaram de 29,00 a 49,00\%. Os CVs das subsubparcelas variaram de 28,00 a $39,00 \%$. Santos (2010) encontrou valores de coeficiente de variação de $33,11 \%$, para escarificadores com diferentes números de hastes.

Nas variáveis DRDE, DRTE e DRTD, pelo teste de Tukey para comparação das médias de operações do cultivo mínimo, em cada rotação do motor, observou-se que as maiores médias foram obtidas na operação de escarificação, em quaisquer das rotações utilizadas (Tabela 4). Como foi explicado anteriormente, isso pode ter ocorrido pelo maior requerimento de força de tração para a operação de escarificação, (Tabela 4).

Resultado semelhante foi encontrado por Rodrigues (2009), para a operação de escarificação, quando obteve valor médio de $19,63 \%$ de deslizamento dos rodados, ao avaliar a resposta da cultura do sorgo em quatro velocidades de deslocamento e quatro sistemas de manejo de solo.

As menores médias foram observadas na operação de pulverização, nas três rotações do motor. Esperava-se por este resultado, haja vista que a força de tração requerida pelo pulverizador é mínima, o que provocou índices baixos de deslizamento.

As variáveis DRDE, DRTE e DRTD não variaram em função da rotação em cada operação de trabalho, segundo o modelo de regressão linear simples. Pelo fato de a rotação não ter influenciado o DRDE, DRTE e DRTD, as equações das retas são constituídas pelas médias dos valores observados das variáveis, os valores médios foram de:

Para a variável DRDE: $\widehat{Y}_{\text {Esc }}=17,89 \% ; \widehat{Y}_{\text {Pulv }}=3,37 \%$; $\hat{\mathrm{Y}}_{\text {Semead }}=6,27 \%$;

Para a variável DRTE: $\widehat{Y}_{\text {Esc }}=18,61 \%$; $\widehat{Y}_{\text {Pulv }}=3,08 \%$; $\hat{\mathrm{Y}}_{\text {Semead }}=12,74 \%$;

Para a variável DRTD: $\widehat{Y}_{\text {Esc }}=12,25 \%$; $\widehat{Y}_{\text {Pulv }}=2,75 \%$; $\widehat{\mathrm{Y}}_{\text {Semead }}=10,70 \%$.

Como discutido anteriormente, isto foi confirmado por Silveira (2008) que não constatou influência da velocidade de operação e da rotação do motor. Saliente-se que tal resultado evidencia, pela análise de regressão, que o deslizamento dos rodados do trator comportou-se como uma variável independente da velocidade de operação e da rotação do motor.

Observou-se diferença estatística entre médias de marchas para DRTD, quando se trabalhou com a menor rotação, sendo a menor média observada com a marcha B1 (Tabela 5). 
Mahl (2006) também observou que, com o aumento da velocidade de 5,50 para 10,10 $\mathrm{km} \mathrm{h}^{-1}$, houve aumento no índice de patinagem de 16,60\%, ao se avaliar os desempenhos operacional e energético de uma semeadora-adubadora de plantio direto, em dois tipos de solos, com distintas vegetações e com diferentes velocidades de semeadura, elementos de corte e sulcadores.

Como em cada operação do cultivo mínimo, em cada marcha utilizada não foi detectada regressão significativa do DRTD em função da rotação do motor, os valores médios foram de: $\widehat{\mathrm{Y}}_{\mathrm{A} 2}=8,22 \% ; \widehat{\mathrm{Y}}_{\mathrm{A} 3}=9,71 \% \mathrm{e}$ $\widehat{\mathrm{Y}}_{\mathrm{B} 1}=7,79 \%$.

Em qualquer marcha utilizada, as maiores médias de DRDD foram observadas na operação de escarificação no cultivo mínimo (Tabela 6), por ser a operação que apresenta maior requerimento de força de tração.

Apenas na operação de escarificação observaram-se diferenças entre as médias de marchas para DRDD, sendo a menor média conseguida trabalhando-se na marcha A2 como demonstrado na (Tabela 6).

\section{Deslizamento das rodas motrizes do trator no plantio direto}

Na análise de variância para deslizamento em cada roda do trator, no plantio direto, não foi observada significância da interação tripla entre os fatores em nenhuma das rodas. Para o DRDE, DRTE e DRTD, verificou-se o efeito significativo somente da operação; para o DRDD, foram observados os efeitos isolados de operações, bem como o efeito da interação (rotação x operação).

Para DRTD, observaram-se maiores valores de CV nas parcelas (operações); este fato foi notado no cultivo mínimo e repetiu-se no plantio direto, e pode ser devido à inclinação do terreno e à grande quantidade de cobertura vegetal na área, fazendo com que o rodado do trator perdesse a aderência ao solo, proporcionando maiores variações de deslizamento nas rodas do lado direito do trator. Verificou-se, também, que o DRDE apresentou o menor coeficiente de variação nas subparcelas (marcha) (27,53\%) comparando-se com os deslizamentos nas demais rodas, os quais variaram de 34 a $41,00 \%$. Os CVs das subsubparcelas variaram de 27,00 a 60,00\%.

Observa-se, pela Tabela 7, que houve diferenças significativas entre as médias do DRDD para as operações de trabalho, em todas as rotações avaliadas, que pode ter acontecido porque a força requerida para a operação de pulverização foi muito pequena e a força requerida para a semeadura foi bem maior, o que provocou maior índice de deslizamento do rodado do trator (Tabela 7); um outro fator que deve ser levado em consideração é o grande volume de cobertura vegetal de braquiária, que induz à maior dificuldade de aderência do rodado.

A regressão da variável DRDD, em função da rotação do motor, em cada operação, independentemente da marcha, não foi significativa. Adota-se aqui a mesma justificativa feita para o preparo convencional e cultivo mínimo,

Tabela 4. Valores médios de deslizamento da roda dianteira esquerda (DRDE \%), deslizamento da roda traseira esquerda (DRTE \%) e deslizamento da roda traseira direita (DRTD \%) em cada operação do cultivo mínimo, por rotação de trabalho do motor do trator

\begin{tabular}{|c|c|c|c|c|c|c|c|c|c|}
\hline \multirow{3}{*}{ Operação } & \multicolumn{3}{|c|}{ DRDE } & \multirow{2}{*}{\multicolumn{3}{|c|}{$\frac{\text { DRTE }}{\text { Rotacão (rpm) }}$}} & \multicolumn{3}{|c|}{ DRTD } \\
\hline & \multirow[b]{2}{*}{1600} & \multirow[b]{2}{*}{1900} & \multirow[b]{2}{*}{2200} & & & & \multirow[b]{2}{*}{1600} & \multirow[b]{2}{*}{1900} & \multirow[b]{2}{*}{2200} \\
\hline & & & & 1600 & 1900 & 2200 & & & \\
\hline Escarificação & 23,45 a & 15,28 a & 14,93 a & 14,97 a & $22,52 \mathrm{a}$ & 18,34 a & $9,11 \mathrm{a}$ & 13,39 a & $14,26 \mathrm{a}$ \\
\hline Pulverização & 3,56 b & $3,41 b$ & $3,13 \mathrm{~b}$ & 3,11 b & 3,82 c & 2,30 b & $2,57 \mathrm{a}$ & 2,83 b & $2,85 \mathrm{~b}$ \\
\hline Semeadura & $5,53 \mathrm{~b}$ & $6,64 \mathrm{~b}$ & $6,65 \mathrm{~b}$ & 9,68 a & $9,90 \mathrm{~b}$ & 18,63 a & $7,83 \mathrm{a}$ & $9,23 a b$ & $15,05 \mathrm{a}$ \\
\hline DMS & & 4,96 & & & 5,47 & & & 9,10 & \\
\hline
\end{tabular}

Médias seguidas de mesma letra, na coluna, não diferem estatisticamente pelo teste de Tukey a 5\% de significância.

Tabela 5. Valores médios de deslizamento da roda traseira direita (DRTD \%) em cada marcha utilizada no cultivo mínimo, por rotação de trabalho do motor do trator

\begin{tabular}{lccc}
\hline Marcha & \multicolumn{3}{c}{ Rotação (rpm) } \\
\hline A2 & $\mathbf{1 6 0 0}$ & $\mathbf{1 9 0 0}$ & $\mathbf{2 2 0 0}$ \\
A3 & $6,80 \mathrm{a}$ & $7,74 \mathrm{a}$ & $10,11 \mathrm{a}$ \\
B1 & $9,00 \mathrm{a}$ & $8,56 \mathrm{a}$ & $11,55 \mathrm{a}$ \\
\hline
\end{tabular}

DMS $=2,65$

Médias seguidas de mesma letra, na coluna, não diferem estatisticamente pelo teste de Tukey a 5\% de significância.
Tabela 6. Valores médios de deslizamento da roda dianteira direita (DRDD \%) em cada combinação de operação e marcha no cultivo mínimo

\begin{tabular}{lcrr}
\hline \multirow{2}{*}{ Operação } & A2 & A3 & B1 \\
\cline { 2 - 4 } & $13,53 \mathrm{aB}$ & $19,57 \mathrm{aA}$ & $17,68 \mathrm{aA}$ \\
\hline Escarificação & $3,38 \mathrm{bA}$ & $3,95 \mathrm{bA}$ & $2,88 \mathrm{bA}$ \\
Pulverização & $7,62 \mathrm{abA}$ & $7,75 \mathrm{bA}$ & $6,61 \mathrm{bA}$ \\
Semeadura & & DMS Linhas = 3,62 \\
\hline DMS Colunas $=7,80$ & & \multicolumn{3}{c}{ Marcha } \\
Médias seguidas de mesma letra minúscula, na coluna, e maiúscula, \\
na linha, não diferem estatisticamente pelo teste de Tukey a 5\% de \\
significância.
\end{tabular}

Rev. Ceres, Viçosa, v. 59, n.3, p. 330-336, mai/jun, 2012 
sendo representada pela média dos valores da variável, os valores médios foram de: $\mathrm{v}_{\text {pul }}=3,27 \%$ e $\mathrm{v}_{\text {sem }}=7,65 \%$.

Houve diferenças significativas entre as médias de operação de trabalho, para as variáveis DRDE, DRTE e DRTD, no plantio direto (Tabela 8), sendo as maiores médias verificadas na operação de semeadura, pela maior força requerida para movimentação da semeadora-adubadora, o que provocou maiores índices de deslizamento.

Cortez et al. (2008), com o objetivo de avaliar o desempenho de um trator agrícola, sob sistemas de preparo do solo em plantio direto e convencional, juntamente com três marchas na operação de semeadura da crotalária, encontraram o valor de $8,50 \%$ de deslizamento do rodado do trator, durante a semeadura, sob plantio direto, valor este próximo do encontrado neste trabalho.

Observou-se que as variáveis DRDE, DRTE e DRTD não variaram em função da rotação do motor, apresentando regressão linear não significativa. Pelo fato de a rotação não ter influenciado o DRDE, o DRTE e o DRTD, as equações das retas são constituídas pelas médias dos valores observados para as variáveis, os valores médios foram de: $\hat{\mathrm{Y}}_{\mathrm{DRDE}}=4,76 \% ; \hat{\mathrm{Y}}_{\mathrm{DRTE}}=7,08 \% ; \hat{\mathrm{Y}}_{\mathrm{DRTD}}=6,37 \%$.

Tabela 7. Valores médios de deslizamento da roda dianteira direita (DRDD \%) em cada operação do sistema plantio direto, por rotação de trabalho do trator

\begin{tabular}{lccc}
\hline \multirow{2}{*}{ Operação } & \multicolumn{3}{c}{ Rotação (rpm) } \\
\cline { 2 - 4 } & $\mathbf{1 6 0 0}$ & $\mathbf{1 9 0 0}$ & $\mathbf{2 2 0 0}$ \\
\hline Pulverização & $4,32 \mathrm{~b}$ & $2,31 \mathrm{~b}$ & $3,17 \mathrm{~b}$ \\
Semeadura & $8,67 \mathrm{a}$ & $5,20 \mathrm{a}$ & $9,07 \mathrm{a}$ \\
\hline
\end{tabular}

DMS $=1,594$

Médias seguidas de mesma letra, na coluna, não diferem estatisticamente pelo teste de Tukey a 5\% de probabilidade.

Tabela 8. Valores médios de operação para as variáveis, deslizamento da roda dianteira esquerda (DRDE \%), deslizamento da roda traseira esquerda (DRTE \%) e deslizamento da roda traseira direita (DRTD \%) no sistema plantio direto

\begin{tabular}{lccc}
\hline Operação & DRDE & DRTE & DRTD \\
\hline Pulverização & $3,21 \mathrm{~b}$ & $3,35 \mathrm{~b}$ & $2,74 \mathrm{~b}$ \\
Semeadura & $6,30 \mathrm{a}$ & $10,80 \mathrm{a}$ & $9,99 \mathrm{a}$ \\
\hline DMS & 1,59 & 3,34 & 7,24 \\
\hline
\end{tabular}

Médias seguidas de mesma letra, na coluna, não diferem estatisticamente pelo teste de Tukey a 5\% de significância.

\section{CONCLUSÕES}

No preparo convencional, o maior índice de deslizamento ocorre na operação de semeadura; no cultivo mínimo, ocorre na operação de escarificação e, no plantio direto, na operação de semeadura.

Em nenhuma das variáveis foi verificado efeito da rotação do motor.

\section{REFERÊNCIAS}

Almeida RAS, Silva CAT \& Silva SL (2010) Desempenho energético de um conjunto trator-semeadora em função do escalonamento de marchas e rotações do motor. Revista Agrarian, 3:63-70.

ASABE (2006) American Society of Agricultural and Biological Engineers. ASAE EP 496.3 Agricultural Machinery Management. In: ASABE Standards 2006. St. Joseph, ASABE. p.385-390.

Chaila S (1986) Métodos de evaluacion de malezas para estudios de poblacion y control. Malezas, 14:1-78.

Chioderoli CA, Furlani CEA, Silva RP, Gitti DC, Kaneko FH \& Roman RAA (2010) Desempenho de semeadora-adubadora em função do preparo de solo e espaçamento da cultura do milho. Pesquisa Agropecuária Tropical, 40:462-467.

CONAB - Companhia Nacional de Abastecimento (2011) Acompanhamento da safra brasileira: grãos, sétimo levantamento. Disponível em: <www.conab.com.br>. Acessado em: 18 de agosto de 2011.

Cortez JW, Furlani CEA, Silva RP \& Grotta DC (2008) Efeito residual do preparo do solo e velocidade de deslocamento na operação de semeadura da Crotalaria juncea. Scientia Agraria, 9:357-362.

EMBRAPA - Empresa Brasileira de Pesquisa Agropecuária (1997) Centro Nacional de Pesquisa de solos. Manual e métodos de análise do solo. $2^{\mathrm{a}}$ ed. Rio de Janeiro, Embrapa. 212p.

EMBRAPA - Empresa Brasileira de Pesquisa Agropecuária (2009) Centro Nacional de Pesquisa de Solos. Sistema Brasileiro de Classificação de Solos. Brasília, Embrapa Solos. 366 p.

Furlani CEA, Lopes A, Silva RP \& Reis GN (2005) Exigências de uma semeadora-adubadora de precisão variando a velocidade e a condição da superfície do solo. Ciência Rural, 35:920-923.

Gabriel Filho A, Lanças KP, Leite F, Acosta JJB \& Jesuino PR (2010) Desempenho de trator agrícola em três superfícies de solo e quatro velocidades de deslocamento. Revista Brasileira de Engenharia Agrícola e Ambiental, 14:333-339.

Llanillo RF, Richart A, Tavares Filho J, Guimarães MF \& Ferreira RRM (2006) Evolução de propriedades físicas do solo em função dos sistemas de manejo em culturas anuais. Semina: Ciências Agrárias, 27:205-220.

Machado ALT, Reis AV, Moraes MLB \& Alonço AS (2005) Máquinas de preparo do solo, semeadura, adubação e tratamentos culturais. $2^{\mathrm{a}}$ ed. Pelotas, Editora e Gráfica Universitária UFPel. 253p.

Mahl D (2006) Desempenho operacional de semeadora em função de mecanismos de corte, velocidade e solos, no sistema plantio direto do milho. Tese de Doutorado. Universidade Estadual Paulista "Júlio de mesquita Filho"/UNESP, Botucatu. 143p.

Masiero FC (2010) Determinação do rendimento na barra de tração de tratores agrícolas com tração dianteira auxiliar (4x2 TDA). Dissertação de Mestrado. Universidade Estadual Paulista “Júlio de mesquita Filho”/UNESP, Botucatu. 79p.

Rodrigues JGL (2009) Desempenho operacional de máquinas agrícolas na implantação da cultura do sorgo forrageiro. Tese de Doutorado. Universidade Estadual Paulista "Júlio de mesquita Filho"/UNESP, Botucatu. 94p.

Santos MS (2010) Parâmetros mecânicos de tração em sistemas de cultivo de melancia. Dissertação de Mestrado. Universidade Federal de Santa Maria, Santa Maria. 82p.

Silva FAS \& Azevedo CAV (2002) Versão do programa computacional Assistat para o sistema operacional Windows. Revista Brasileira de Produtos Agroindustriais, 4:71-78.

Silveira JCM (2008) Desempenho operacional de um conjunto tratorsemeadora em função da velocidade e rotação no eixo do motor. Tese de Doutorado. Universidade Federal de Viçosa, Viçosa. 145p.

Toledo A, Furlani CEA, Silva RP, Lopes A \& Dabdoub MJ (2010) Comportamento espacial da demanda energética em semeadura de amendoim em Latossolo sob preparo convencional. Engenharia Agrícola, 30:459-467. 